\title{
Risk Management of Road Engineering Project Based on Analytic Hierarchy Process
}

\author{
Shanxiang CHEN, Xu LUO*, Xinping LI, Xinsha FU
}

\begin{abstract}
In the construction process of road engineering, risks are everywhere. To do a good job in the risk management of road engineering projects, finding the risk factors of road engineering projects is an important part of it. This article introduces the characteristics of project risks and the process of risk management. The AHP method is applied to the risk analysis of road engineering projects to realize the ranking of risk factors, the evaluation of the total risk system, and the selection of risk response measures. This article conducts risk evaluation on the project, finds out important risk factors, and effectively controls them. This paper adopts the analytic hierarchy process on the overall risk management of road engineering projects. Finally, it comprehensively considers the systemic and non-systematic risks faced by road engineering, and specifically involves macro policy and economic risks, as well as project initiation and project construction. The risks and capital risks, and other links considered the internal and external factors of the road-engineering project. In this way, the project risk has been comprehensively measured by a combination of qualitative and quantitative methods, and the effective management of the project has been finally realized.
\end{abstract}

Keywords: Analytic Hierarchy Process; risk factors; risk management; road engineering

\section{INTRODUCTION}

With the rapid development of the social economy and the continuous improvement of people's quality of life, China has mainly reflected the improvement of people's travel methods and changes. Then people's pursuit of continuous improvement in travel modes has created a diversification of modern transportation modes, such as modern high-speed rail, inter-city high-speed rail, highways, etc. Then, in the process of continuous improvement of transportation methods, the routes will inevitably cross mountains and rivers. The construction of transportation routes in these special areas reflects the importance of our engineers. According to statistics, the total length of China's railways and road projects ranks first in the world, and China's road and railway transportation network has been improved, but there is still a long way to go before the transportation plan that meets the national requirements. It means that road engineering projects will still be widespread in our country's engineering [1]. Road engineering includes construction underground, mountain, underwater, etc., which are buildings for road vehicles or railway trains. Road engineering construction mainly involves road planning, route survey, route design, construction, and penetration control survey [2]. China's road engineering construction has achieved great results. However, China's road engineering risk management lags far behind the development of road engineering technology. Safety accidents often occur in the process of road engineering construction, and the losses caused are very serious. Therefore, there is an urgent need to speed up risk management and control in the construction phase of road engineering projects in China.

New technologies and new materials are widely used in road engineering projects, and the social environment and natural environment are becoming more and more complex, so some uncertain factors and the risk loss have increased day by day. Once these uncertain factors occur, it will seriously affect some of the main objectives of the project. However, the main body of the engineering project is often due to various problems, such as insufficient knowledge or insufficient power to control, resulting in unexpected results [3]. Sometimes not only the expectations of the main body of the project cannot be met, but also various large and small losses will occur. The importance of risk management for road engineering projects can be seen. This article has conducted research and analysis on road engineering project risk management. The project risk management is as follows. The construction party is a specialized organization established based on the overall level of project risk, with reference to the importance of the project to the organization and the risk management plan. It is a very important part of the project management organization and is carried out under the leadership of the project manager. With the continuous improvement of road engineering project risks management methods, tools and technologies, coupled with people's continuous deepening of risks, road engineering risk management project is also occupying an increasingly important position. Therefore, the establishment of risk management agencies should consider many uncertain factors, such as the project risk level of the road engineering company or the construction party [4]. These factors restrict the organizational form, staffing and management system of the risk management agency. At the same time, a reasonable organization and high-quality risk management personnel are the key factors for successful risk management project. The construction process of a project has many characteristics, such as a large amount of investment and a large scale, a long construction period, complex technology and high requirements. In this process, there are many uncertain factors, random factors, and continuous changes. The resulting risks will directly threaten the smooth progress of the project. The risks may lead to the implementation of the project to be out of control.

The construction safety management in road engineering is helpful to the overall safety and quality control. The contribution of this paper is as follows. Risk assessment and decision-making control model can be formed to identify key risks and propose risk control countermeasures. The analysis and research results of this article have certain guiding significance for the risk management of road engineering projects in our country. This paper uses the analytic hierarchy process to study the risk management of road engineering projects. The risk 
evaluation is mainly based on the various links in the construction safety management. The system architecture method reflects the whole project, which can reflect various problems in the system, and make timely changes and improvements based on the problems raised in combination with reasonable and scientific suggestions. Through systematic follow-up, the personal safety of construction personnel can be better maintained, and the probability of occurrence of safety risks in on-site construction can be gradually reduced.

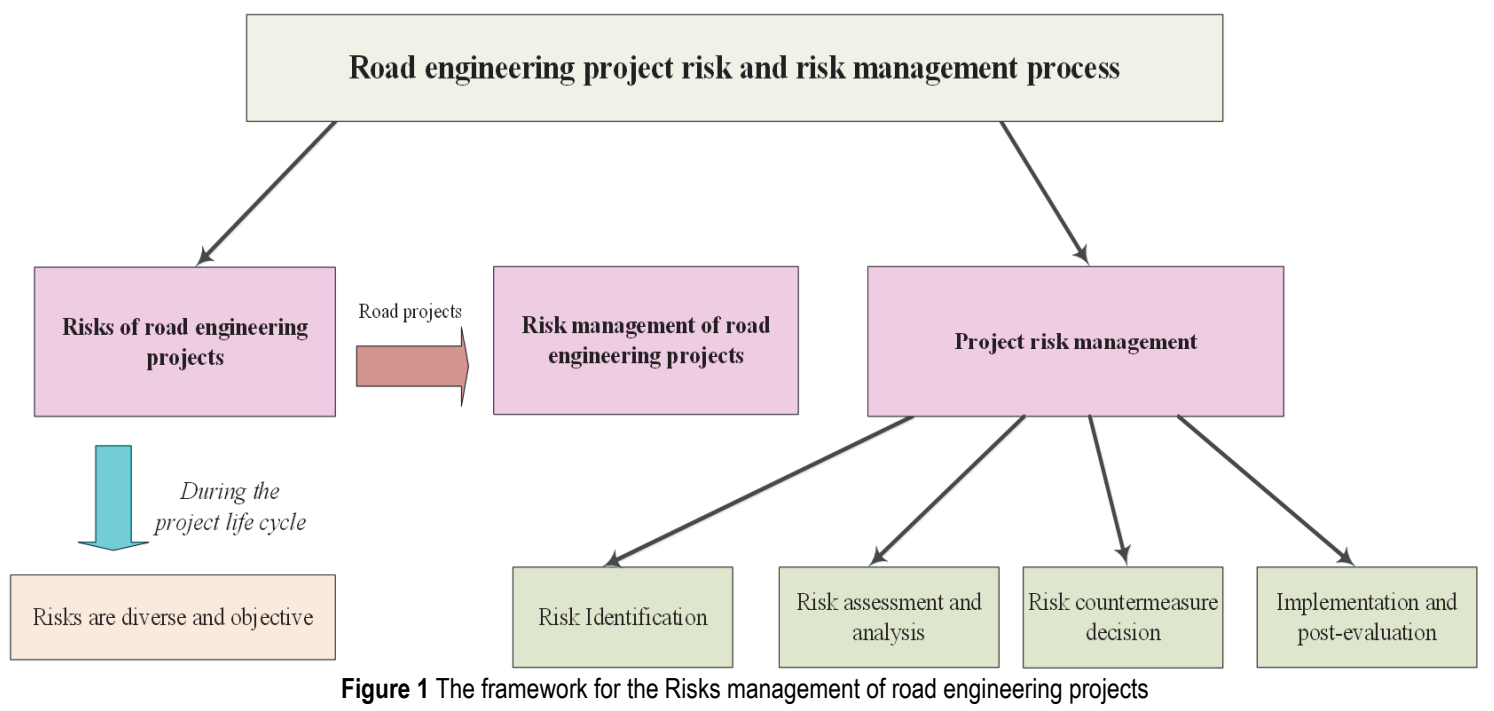

\section{ROAD ENGINEERING PROJECT RISK AND RISK MANAGEMENT PROCESS}

China's transportation network is constantly improving, and the tunnel line as a transportation line is indispensable. Therefore, for tunnel engineering projects, it is a mainstream project, involving soil tunnels and rock tunnels, no matter what types of tunnels are designed to use underground space to achieve certain purposes [5]. For road engineering, a special large-scale construction project and as an important part of the road transportation network, road engineering has the characteristics of large scale, long cycle, high technical difficulty, numerous participants, and complex contractual relationships.

\subsection{Risks of Road Engineering Projects}

Road engineering project risk refers to the risk of project loss due to certain uncertainties that may cause the project to deviate from the target during the project life cycle. The risks of engineering projects have the following characteristics.

(1) Risks are diverse, and there are many types of risks in a project, such as political risks, economic risks, legal risks, natural risks, contract risks, personnel risks, etc. And there are complex internal links between these risks. (2) Risks are objective. Risks are everywhere and all the time, and risks are inevitable. (3) Risks exist throughout the entire project cycle. From the completion of the decisionmaking project, risks always exist. (4) Risks have certain regularity and can be predicted. It is important for people to establish risk awareness, strengthen risk management, and comprehensively control risks.

\subsection{Risk Management of Road Engineering Projects}

Engineering project risk management refers to the project undertaking unit predicting, identifying, analyzing, and evaluating the risks that may be encountered during the life cycle of the project, and on this basis, adopting measures, proposing countermeasures, reducing risk losses, and achieving project goal management Scientific management methods.

\subsection{Project Risk Management Process 2.3.1 Risk Identification}

As the first step of risk management, risk identification includes the determination of the source of risk, the conditions for risk generation, the characteristics of the risk, and the possible conditions for the risk factors in the project [6]. In this link, you should first be familiar with the components of the project, grasp the nature of the uncertain factors and their relationships, analyze the impact of environmental factors on the project implementation process, which use reasonable steps and methods to check various events that may pose risks to the project.

\subsubsection{Risk Assessment and Analysis}

Risk assessment and analysis is what we usually call risk assessment", which uses qualitative and quantitative methods to deeply analyze the identified risk elements, and estimate the probability of risk occurrence and the level of interference. In addition, through the analysis and weighing of risk factors, the overall level of project risk can be evaluated.

\subsubsection{Risk Countermeasure Decision}

Risk countermeasure decision-making is the process of determining the best countermeasure combination of construction project risk. According to the results of the risk assessment, the risk response measures are formulated without eliminating or reducing the adverse consequences caused by the risk. When formulating risk response 
strategies, the project objectives should be combined with comprehensive consideration of the hazard degree of the risk and the cost of risk prevention and control. Although different projects have different risk response measures, risk prevention and control have a set of basic strategies, such as risk transfer, risk avoidance, loss control, and risk retention.

\subsubsection{Implementation and Post-Evaluation}

After making the right decision on the risk, the implementation process is very important. In the implementation process, the implementation should be monitored, the risk prevention and control plan should be adjusted in real time, and the management measures to ensure the smooth implementation of the plan should be adjusted in real time. Finally, the risk reduction effect should be comprehensively evaluated, and the implementation effect and differences should be evaluated.

The risk factors existing in the project implementation process is an important prerequisite for scientifically carrying out risk management and control work. How to tap the key elements of various risk factors is the top priority of risk management [7]. The project department must first establish a rigorous risk evaluation system, and use the system to evaluate the identified risk elements. Whether the evaluation of risk elements is accurate and objective mainly depends on whether the design of the evaluation system is reasonable. The following will introduce the risk evaluation index system constructed based on the analytic hierarchy process.

\section{RISK MANAGEMENT OF ROAD ENGINEERING PROJECT BASED ON AHP}

\subsection{Establishment of Risk Management Evaluation System} for Road Engineering Project

Generally, when building a road engineering project safety management, it is based on systematic scientific method, through a fully applicable operation interface and scheme. At this time, the entire system should objectively reflect the characteristics of the entire safety management, and the difficulties in the proposed process. Based on the entire evaluation index, strengthen the internal connection of the project, mainly as follows. (1) To clarify the entire evaluation Background, on this basis, to achieve the purpose of safety assessment, and make risk preparations. (2) Through the determination of the evaluation purpose, the hierarchical structure design is combined with the overall plan. (3) Relevant personnel should summarize the files of the entire industry based on the system data and extract effective evaluation indicators. (4) After the initial rating indicators obtain satisfactory results of the integrity system architecture, the indicators shall be used as the main purpose to reflect the stability and reliability of the overall safety management system. Combined with expert opinions as the leading factor, the overall indicators are screened and adjusted [8].

\subsection{Risk Management Contents of Road Engineering Projects}

Project risk management is a scientific and systematic management method. It is a huge systematic project. It means that risk management personnel use risk management methods and tools and follow the principles and procedures of risk management to control the existing problems in the project life cycle. According to the magnitude of the risk value, this article adopts targeted risk response strategies and management and control measures to keep the project risk under control, to achieve the goal of minimizing the impact of risk on project losses. Road engineering project risk management is a part of project risk management. It refers to the use of risk management techniques during the construction phase of the project to identify and manage risks during the construction phase, and take targeted preventive measures to reduce the occurrence of construction risks. Therefore, there are generally two goals for project risk management. One is to take various effective measures to avoid risks to the greatest extent possible. The second is to reduce the impact of risks on the project through risk management and control measures or strategies, and to ensure the normal operation of the project to the greatest extent. In short, risk planning and identification must be done in the early stage of the baby. The risk management process includes four steps: risk identification, risk evaluation, risk decisionmaking, and risk supervision. The various procedures and steps of project risk management form a dynamic circle, and the various stages are closely connected and a circle of continuous improvement. Risk identification is the primary task of risk management. Only by doing a good job in risk identification, and comprehensively identifying the risks of road engineering projects can the effectiveness of project management be guaranteed from the source. Risk evaluation refers to the quantitative evaluation of risks, to more effectively understand the magnitude of various risks. Risk decision-making refers to the use of targeted improvement measures based on the results of risk evaluation. Risk prevention and supervision refers to the monitoring of the effects of measures taken to respond to risks.

AHP is an effective tool for analyzing complex management issues. It has the structural characteristics of "multiple criteria, multiple objectives, strong methodologies, and strong systemicity", and it has strong practicability. It has been popularized in many fields such as politics, economy, scientific research, etc. The results are outstanding. Problems that are difficult to carry out qualitative and quantitative analysis in risk management can all be well resolved through the analytic hierarchy process. An analysis combines qualitative analysis and quantitative analysis, its essence is to arrange an intricate problem into a hierarchical structure according to its constituent elements and the domination relationship between the elements, and then oppose the two according to the degree of importance [9]. After the comparison, the ranking is performed, and finally, an experienced analyst determines the relative importance of each element through the analysis and comparison of the ranking results.

This article uses analytic hierarchy process that can be divided into five steps.

(1) Establish a hierarchical structure model.

According to the actual situation, the model can be further subdivided into scheme layer, criterion layer and target layer. Complex problems can be divided into the 
overall goal level, sub-goal level, criterion level (or constraint factor level), scheme level, or a structure with more levels. Determine the evaluation target, evaluation plan, evaluation criteria and indicator elements, build a systematic hierarchical structure model, and then put each work package in the risk identification mode to identify and analyze the risk elements, and integrate the risk identification results. Construct the risk analysis hierarchical model of the work package.

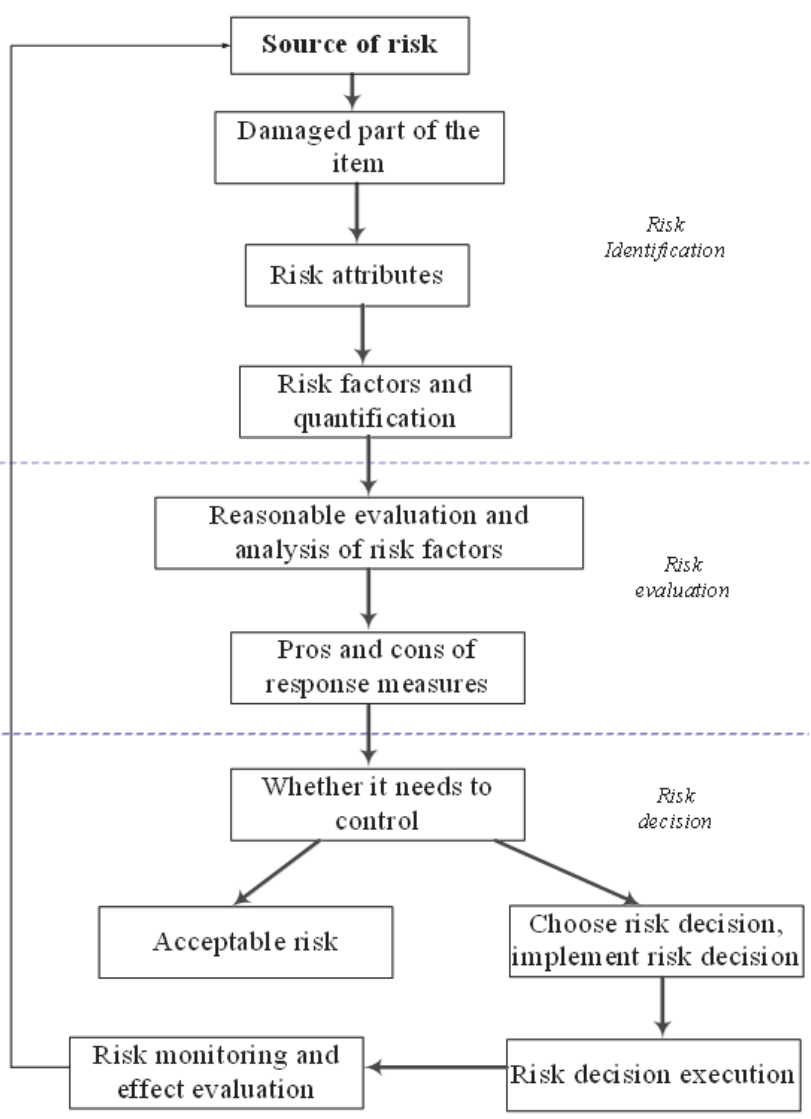

Figure 2 Steps of Analytic Hierarchy Process

(2) Construct the judgment matrix.

Experienced technicians use the method of comparative scoring to determine the relative importance between the upper and lower elements. The analytic hierarchy process is based on the judgment matrix to analyze and compare project risks. The construction of the judgment matrix is undoubtedly the most important step in the analytic hierarchy process. In the indicator system established in the first step, there are $N$ impact factors under a certain level of indicators, respectively. Any two of the impact factors are compared in pairs, and a matrix is used to contain all the results of the pairwise comparison, which is the judgment matrix. The process of comparison usually follows certain standards, such as the Saaty1-9 scaling method. The scores and corresponding meanings are shown in Tab. 1.

(3) The level list is sorted and checked for consistency.

Hierarchical single sorting is to determine the degree of influence of the elements contained in a certain layer on the upper-level elements to be analyzed and summarized through the hierarchical single sorting method. The principle is as follows. The eigenvector of the judgment matrix is obtained through calculation based on the matrix analysis method [9]. The weight value of the element of the level to the element of the upper level is reflected by the feature vector, and the result of the single sorting is these weight values. It is recommended to use the square root method and the sum product method to calculate the eigenvectors of the analysis matrix. These two approximate solutions fully meet the design requirements.

Table 1 Satty 1-9 scaling method

\begin{tabular}{|l|c|}
\multicolumn{1}{|c|}{$\begin{array}{c}\text { Comparison degree description } \\
\text { (indicator importance description) }\end{array}$} & Score \\
\hline The former is the most important & 8 \\
\hline The former is much more important than the latter & 6 \\
\hline The former is more important than the latter & 4 \\
\hline The former is more important than the latter & 2 \\
\hline The same & 1 \\
\hline The latter is more important than the former & $1 / 2$ \\
\hline The latter is more important than the former & $1 / 4$ \\
\hline The latter is much more important than the former & $1 / 6$ \\
\hline The latter is important & $1 / 8$ \\
\hline
\end{tabular}

The third step is the evaluation matrix calculation.

(1) Standardization: Standardize each column of the evaluation matrix $\boldsymbol{R}$, namely Application case of analytic hierarchy process in a project.

$$
\overline{\boldsymbol{R}}=\left[\bar{r}_{i j}\right]=\left[\frac{r_{i j}}{\sum_{k=1}^{n} r_{k j}}\right]
$$

(2) The sum of $\overline{\boldsymbol{R}}$ is as follows.

$$
\bar{U}=\left[U_{i}\right]^{\mathrm{T}}=\sum_{j=1}^{n} \bar{r}_{i j}
$$

(3) Normalize $\bar{U}$.

(4) Level total ranking.

Through the calculation and analysis of each level, this article sorts and counts the relative weight of each indicator according to the calculation results. The relative weight of each indicator or evaluation plan in the hierarchical target is determined according to the calculated weight ranking result.

(5) Calculate the comprehensive total score.

This article counts the scores of the evaluation schemes and evaluation indicators and then substitutes them into mathematical formulas to obtain the weighted average [10]. The risk with the highest total score is the greatest.

\subsection{Analytic Hierarchy Process to Assess Risk}

The analytic hierarchy process is used to determine the main risk factors. Let $R$ be the construction project risk, $U 1$ the construction management risk, $U 2$ the natural risk, $U 3$ the economic and legal risk, $V 1$ the material risk, $V 2$ the capital risk, and $V 3$ the capital risk, $V 4$ is construction risk, $V 5$ is manpower risk. Establish a hierarchical analysis model, see Fig. 3.

Fig. 3 shows the Analytic hierarchy model diagram. After expert experience evaluation, scoring is summarized 
into the following $U 1-V$ level pairwise judgment matrix.

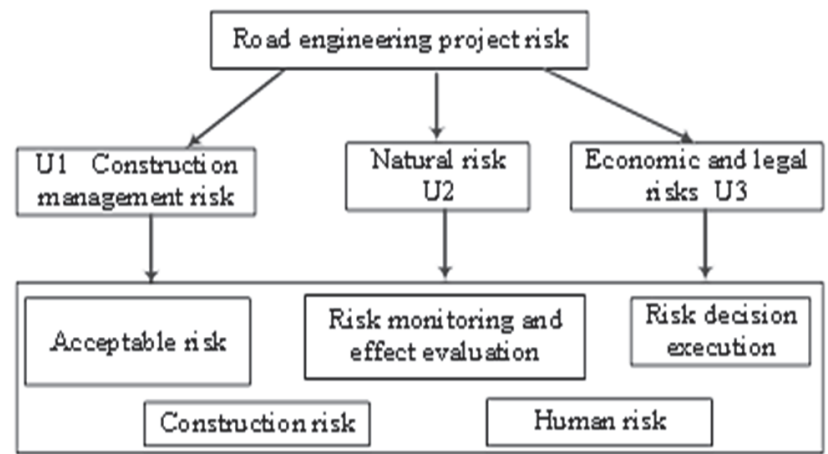

Figure 3 Steps of Analytic Hierarchy Process

Table 2 U1-V level judgment matrix

\begin{tabular}{|c|c|c|c|c|c|}
\hline \multicolumn{7}{|c|}{$U 1-V$ level judgment matrix } \\
\hline Risk factors & $V 1$ & $V 2$ & $V 3$ & $V 4$ & $V 5$ \\
\hline$V 1$ & 1 & 3 & 6 & 4 & $1 / 4$ \\
\hline$V 2$ & $1 / 3$ & 1 & 5 & 2 & $1 / 6$ \\
\hline$V 3$ & $1 / 6$ & $1 / 5$ & 1 & $1 / 3$ & $1 / 9$ \\
\hline$V 4$ & $1 / 4$ & $1 / 2$ & 3 & 1 & $1 / 7$ \\
\hline$V 5$ & 4 & 6 & 9 & 7 & 1 \\
\hline
\end{tabular}

Among them, the highest probability is the human risk, and the smallest is the inflation risk. Calculate the $U-V$ level judgment matrix $U$-weight, sort, and check the consistency. First, this paper calculates the geometric mean of each row of elements in the matrix.

\subsection{Risk Evaluation of Road Engineering Project Based on AHP}

In order to clarify the weight value of each risk evaluation index more clearly, this article has carried out a survey and research on the relevant managers of road engineering projects, experts and scholars, and personnel of market risk management institutions, and filled out the corresponding questionnaires. There are 100 questionnaires, and 92 valid questionnaires, with an effective rate of $92 \%$. Please refer to Appendix 1 for details of the questionnaire.

\begin{tabular}{|c|c|c|}
\hline Name & Type & NO. \\
\hline \multirow{2}{*}{ Gender } & Male & 159 \\
\hline & Female & 41 \\
\hline \multirow{4}{*}{ Age } & $18 \sim 25$ & 24 \\
\hline & $26 \sim 40$ & 78 \\
\hline & $41 \sim 55$ & 92 \\
\hline & $>55$ & 14 \\
\hline \multirow{3}{*}{ Education } & College degree and below & 4 \\
\hline & Undergraduate & 90 \\
\hline & Master's degree and above & 106 \\
\hline \multirow{4}{*}{$\begin{array}{l}\text { Length of service / } \\
\text { year }\end{array}$} & $1 \sim 5$ & 9 \\
\hline & $6 \sim 10$ & 51 \\
\hline & $11 \sim 20$ & 128 \\
\hline & $>20$ & 12 \\
\hline \multirow{3}{*}{ Identity Position } & Construction project management staff & 74 \\
\hline & Third-party risk management personnel & 96 \\
\hline & University experts and scholars & 30 \\
\hline
\end{tabular}

By collecting and sorting out the information in the questionnaire, this article processes the information in the questionnaire and obtains the weight value information of each indicator. Taking the second-level indicator policy risk as an example, the following describes the process of determining the weight of three indicators under the second-level indicator policy risk. The determination of the weight of the second-level indicator management risk is determined by collating and collecting the evaluation information of the expert group on the policy risk indicators. This article establishes the policy risk judgment matrix for secondary indicators in Tab. 4.

\begin{tabular}{|c|c|c|c|}
\hline First-level index & Weight & Secondary-level index & Weight \\
\hline \multirow{4}{*}{ Capital risk } & \multirow{4}{*}{0.13} & Capital turnover risk & 0.23 \\
\hline & & Financing risk & 0.04 \\
\hline & & $\begin{array}{l}\text { Risk of rising material prices } \\
\text { and Manpower }\end{array}$ & 0.66 \\
\hline & & Technology introduction risk & 0.07 \\
\hline \multirow{2}{*}{ Environmental risk } & \multirow{2}{*}{0.12} & Environmental pollution risk & 0.46 \\
\hline & & Solid waste risk & 0.54 \\
\hline \multirow{4}{*}{ Schedule risk } & \multirow{4}{*}{0.11} & $\begin{array}{l}\text { Contract risk of construction } \\
\text { parties }\end{array}$ & 0.25 \\
\hline & & $\begin{array}{l}\text { Linkage risks of construction } \\
\text { sub-projects }\end{array}$ & 0.14 \\
\hline & & Outsourced labor price risk & 0.07 \\
\hline & & Construction efficiency risk & 0.54 \\
\hline \multirow{3}{*}{ Quality risk } & \multirow{3}{*}{0.24} & $\begin{array}{l}\text { Material and equipment quality } \\
\text { risk }\end{array}$ & 0.45 \\
\hline & & Employee operational risk & 0.1 \\
\hline & & Risk of lax quality control & 0.45 \\
\hline \multirow{3}{*}{ Technology risk } & \multirow{3}{*}{0.16} & $\begin{array}{l}\text { The unreasonable construction } \\
\text { plan and technology }\end{array}$ & 0.7 \\
\hline & & Risk of outdated equipment & 0.2 \\
\hline & & $\begin{array}{l}\text { Risk of backward construction } \\
\text { technology }\end{array}$ & 0.1 \\
\hline \multirow{4}{*}{ Manage risk } & \multirow{4}{*}{0.15} & $\begin{array}{l}\text { Risk of inadequate project } \\
\text { monitoring }\end{array}$ & 0.11 \\
\hline & & Contract management risk & 0.24 \\
\hline & & Safety production risk & 0.1 \\
\hline & & $\begin{array}{l}\text { Organization and coordination } \\
\text { risk }\end{array}$ & 0.55 \\
\hline \multirow{3}{*}{ Policy risk } & \multirow{3}{*}{0.09} & $\begin{array}{l}\text { Pharmaceutical industry policy } \\
\text { risks }\end{array}$ & 0.25 \\
\hline & & $\begin{array}{l}\text { Risks of rising industry } \\
\text { regulatory standards }\end{array}$ & 0.16 \\
\hline & & Interest rate transaction risk & 0.59 \\
\hline
\end{tabular}

Through the above-mentioned road engineering project risk assessment based on AHP, the following conclusions can be drawn.

The financial risk weight of each criterion level of the road-engineering project is 0.13 , the environmental risk weight is 0.12 , the schedule risk weight is 0.11 , the quality risk weight is 0.24 , and the technical risk weight is 0.16 . The weight of management risk is 0.15 , and the weight of policy risk is 0.09 . It can be seen that quality risk is the key influencing factor of the risk of road engineering projects, followed by technical risk and management risk. Road engineering project managers can focus on monitoring from the aspect of technical risks. In terms of the indicators of the technical risk plan, two experts scored 5 points for the construction plan and the two indicators of unreasonable technology and outdated equipment risks. Therefore, road engineering project managers can control technical risks from the above two indicators.

\section{CONCLUSIONS}

Through the analysis of the current situation of road engineering project risk management, it is pointed out that there are problems in its risk management work such as the absence of a special risk management organization, the 
backward risk identification tools, and the unscientific risk evaluation methods. Based on determining the risk identification process of road engineering projects, this paper determines the road engineering project risk evaluation of AHP. AHP is used to determine the index weights, and evaluation is used to evaluate project risks. AHP is used in the risk evaluation of road engineering projects, and the result shows that the project risk is between average and high. Among them, the unreasonable construction plan and technology, and the risk of backward equipment are indicators that affect the relative technology.

\section{REFERENCES}

[1] Mu, L. L. \& Xing, B. (2015). Investment Risk Analysis of Gas and Pipeline Construction Project Based on the Gray Analytic Hierarchy Process. Proceedings of the $21^{\text {st }}$ International Conference on Industrial Engineering and Engineering Management 2014. https://doi.org/10.2991/978-94-6239-102-4_94

[2] Wu, H., Qian, Z., \& Wang, J. (2020). A safety risk evaluation index system of subway projects based on the analytic hierarchy process. Journal of Physics: Conference Series, 1676(1), 012134. https://doi.org/10.1088/1742-6596/1676/1/012134

[3] Fang, D. B. \& Liu, W. (2011). Research on risk management of engineering project auction. Advanced Materials Research, 219-220, 1523-1527.

https://doi.org/10.4028/www.scientific.net/AMR.219-220.1523

[4] De Oliveira, U. R., Silva Marins, F. A., Rocha, H. M., \& Pamplona Salomon, V. A. (2017). The ISO 31000 standard in supply chain risk management. Journal of Cleaner Production, 151(MAY10), 616-633. https://doi.org/10.1016/j.jclepro.2017.03.054

[5] Razumnikov, S. V. \& Kremneva, M. S. (2015). Decision support system of transition IT-applications in the cloud environment. IEEE, 1-4. https://doi.org/10.1109/SIBCON.2015.7147186

[6] Singh, A. (2017). Quantitative risk management and decision making in construction. Chapter 10: MCDM and the analytic hierarchy process. 177-192. https://doi.org/10.1061/9780784414637.ch10

[7] Zheng, L. X. (2013). Research on project risk management of power engineering based onevaluation method. Applied Mechanics \& Materials, 415, 287-293. https://doi.org/10.4028/www.scientific.net/AMM.415.287

[8] Bharathi, S. V. (2019). Forewarned is forearmed assessment of IOT information security risks using analytic hierarchy process. Benchmarking, 26(8), 2443-2467. https://doi.org/10.1108/BIJ-08-2018-0264

[9] Kayikci, Y., Stix, V., Leblanc, L. J., \& Bartolacci, M. R. (2015). A novel application of a hybrid delphi-analytic hierarchy process (AHP) technique: identifying key success factors in the strategic alignment of collaborative heterarchical transportation networks for supply chains. International Journal of Applied Logistics, 5(1), 52-75. https://doi.org/10.4018/ijal.2014010104

[10] Gao, L. \& Li, X.(2013). Application of evaluation method in engineering project risk management. Advanced Materials Research, 671-674(3), 3087-3090. https://doi.org/10.4028/www.scientific.net/AMR.671-674.3087

[11] Nurdiana, A. \& Wibowo, M. A. (2018). Risk management application at performance based contracts based on project life cycle using AHP method (case study at road maintenance project in Indonesia). Advanced Science Letters. https://doi.org/10.1166/asl.2018.13069

\section{Contact information:}

\section{Shanxiang CHEN}

School of Traffic and Transportation Engineering, Changsha University of Science and Technology, Changsha Hunan, China

\section{Xu LUO}

(Corresponding author)

School of Mechanics and Construction Engineering, Jinan University,

601 Huangpu Avenue West, Guangzhou, China

Email: tluoxu_jnu@163.com

\section{Xinping LI}

School of Civil Engineering and Transportation,

South China University of Technology,

Guangzhou, China

\section{Xinsha FU}

School of Civil Engineering and Transportation, South China University of Technology,

Guangzhou, China 